\title{
Mediciones ambientales del sector educativo en la modalidad virtual del Politecnico Grancolombiano.
}

\author{
Docente \\ Martha Janeth Cifuentes Izquierdo \\ mcifuentes@poligran.edu.co \\ Estudiantes \\ Duber Alexander Castañeda Acevedo
}

Institución Universitaria Politecnico Grancolombiano

Profesional en Gestión de la Seguridad y la salud laboral

El semillero de higiene $y$ seguridad laboral, para este año 2020, se ha trazado una meta importante y es poder evidenciar las condiciones ambientales a las cuales se están exponiendo los docentes en la modalidad de teletrabajo, bajo el proyecto denominado "Mediciones ambientales del sector educativo en la modalidad virtual del Politecnico Grancolombiano". Cuando se piensa este proyecto el mundo no pasaba por la situación actual, el teletrabajo era solo de algunos docentes del Politecnico Grancolombiano, de algunos trabajadores en Colombia y en el mundo. En Colombia esta modalidad de Teletrabajo se enmarca bajo la Ley 1221 de 2008, en donde se establecen normas para promover $y$ regular esta modalidad de trabajo.

Pero esta nueva realidad debido a la pandemia del COVID-19 llega con un término diferente que es el Home Working o trabajo en casa en donde, genera una transformación total de las rutinas de trabajo de todos trabajadores del Politecnico Grancolombiano y de muchos trabajadores en el mundo, modalidad de trabajo que no está legislada, que solo se realiza para darle una continuidad a las organizaciones y darle la probabilidad a los trabajadores a su vez de continuar con su trabajo y así mantener sus ingresos, pero esto no quiere decir que las organizaciones puedan dejar que sus trabajadores, realicen sus actividades sin un mínimo de condiciones básicas en donde se garantice que tanto su salud mental como física no se vean afectadas.

Por lo tanto, sin importar en esta nueva actualidad si la modalidad es de Teletrabajador o de Home Working del docente del Politecnico Grancolombiano, se realizará una encuesta en donde se le preguntará a dichos docentes sobre su percepción de su entorno y otra encuesta sentida de su salud.
Este proyecto se basará bajo apoyos de herramientas virtuales en los lugares en donde desarrolla las actividades el teletrabajador o trabajador por Home Working, de esta manera se pretende identificar los posibles riesgos ambientales a los cuales puede estar expuesto dicho docente, según las condiciones de los espacios escogidos por cada uno para la ejecución de sus actividades.

Con esta investigación, se identifica como una oportunidad para brindarle a los teletrabajadores y a los actuales trabajadores bajo la modalidad de Home Working, pueden reconocer cuales serían los ambientes mas seguros, desde el factor de riesgo físico, con el fin de mitigar las probabilidades de generar enfermedades laborales para el desempeño de sus actividades. Las fases de desarrollo que se trabajaran dentro de este proyecto son:

Fase reconocimiento: Fase que se dio inicio en el mes de mayo, en donde los estudiantes ya han

\section{POLIANTEA}


iniciado a consultar como, bajo que normatividad, que se conoce sobre los riesgos de este tipo de trabajo, en Colombia, Latinoamérica y el mundo.

Fase Diagnóstica: Fase que se desarrolla con el fin de evidenciar la condición actual de los teletrabajadores y Home Working de los docentes del Politecnico Grancolombiano.

Análisis de los resultados
Formulación de una Guía para disponer lugares de trabajo óptimos.

Los resultados esperados bajo este proyecto entonces en una primera fase es la elaboración de una guía que permita que el teletrabajador o trabajador bajo la modalidad de Home Working, puedan reconocer como debe escoger su lugar de trabajo, que debe tener en cuenta para que los riesgos físicos sean mínimos y así garantizar que dicho ambiente no perjudica su salud.

Los estudiantes de este semillero ya han dado grandes pasos de reconocimiento de estos entornos a nivel de consulta, ya tiene una primera capacitación sobre el planteamiento del problema, reconociendo que las consulta debe ser mas fuerte pues es un tema que actualmente se escucha mucho pero que poco sustento investigativo se tiene y es necesario saber más.

\section{POLIANTEA}

